\title{
INFLUÊNCIA DO TIPO E DA QUANTIDADE DE RESÍDUOS VEGETAIS ASSOCIADOS A HERBICIDAS RESIDUAIS NO DESENVOLVIMENTO DA CULTURA DA SOJA $\left({ }^{1}\right)$
}

\author{
NÚBIA MARIA CORREIA $\left({ }^{2 *}\right)$; JULIO CEZAR DURIGAN $\left({ }^{2}\right)$
}

\begin{abstract}
RESUMO
O objetivo do trabalho foi avaliar, em condições de campo e na região originalmente sob cerrado, os efeitos de resíduos vegetais [sorgo de cobertura (híbrido Cober Exp), milheto forrageiro (var. BN2), capim pé-de-galinha (Eleusine coracana) e capim braquiária (Brachiaria brizantha)] e duas quantidades de palha (3,0 e 5,5 $\mathrm{t} \mathrm{ha}^{-1}$, no primeiro ano do estudo, e 3,5 e 5,8 $\mathrm{t} \mathrm{ha}^{-1}$, no segundo), associados a herbicidas residuais (diclosulam a $35 \mathrm{~g} \mathrm{ha}^{-1}$ e imazaquin a $140 \mathrm{~g} \mathrm{ha}^{-1}$ ) aplicados em pré-emergência, no desenvolvimento da cultura da soja. Para tal, foi desenvolvido experimento no ano agrícola 2003/2004 e repetido em 2004/2005, na Fazenda Três Marcos, em Uberlândia (MG). No primeiro ano, após a instalação da cultura da soja, plantas de Eleusine coracana tornaram-se as principais infestantes na cobertura de capim pé-de-galinha. Devido à ausência de controle dessa espécie pelos herbicidas testados, a convivência entre ela e a cultura refletiu negativamente nas plantas de soja. O herbicida imazaquin afetou, indiretamente, as plantas de soja, em virtude do seu controle insatisfatório das plantas daninhas. Nas plantas de soja crescidas sobre cobertura de capim braquiária (nos dois anos) e de capim pé-de-galinha (no segundo ano) observaram-se maior produtividade de grãos, acúmulo de massa e altura de plantas. Os resíduos vegetais de sorgo influenciaram negativamente no desenvolvimento das plantas de soja, nos dois anos. Quanto aos níveis de palha, houve diferença entre eles para milheto forrageiro (no primeiro ano) e sorgo (no segundo ano). O menor nível de milheto forrageiro e o maior de sorgo ocasionaram prejuízos às plantas de soja.
\end{abstract}

Palavras-Chave: cerrado, cobertura morta, controle químico, manejo integrado, plantas daninhas, sistema de semeadura direta.

\section{ABSTRACT \\ INFLUENCE OF THE TYPE AND AMOUNT OF CROP RESIDUES COMBINED WITH RESIDUAL HERBICIDES ON SOYBEAN DEVELOPMENT}

This work was conducted in the agricultural years 2003/2004 and 2004/2005, at the "Três Marcos" Farm, Uberlândia (MG), Brazil. It was aimed to evaluate the effect of crop residues [coverage sorghum (hybrid Cober Exp), forage millet (var. BN2), finger millet (Eleusine coracana) and St. Lucia Grass (Brachiaria brizantha)] in two amounts: 3.0 and $5.5 \mathrm{t} \mathrm{ha}^{-1}$ in the first year and 3.5 and $5.8 \mathrm{t} \mathrm{ha}^{-1}$, in the second year, combined with residual herbicides: diclosulam at $35 \mathrm{~g} \mathrm{ha}^{-1}$ and imazaquin at $140 \mathrm{~g} \mathrm{ha}^{-1}$, applied at preemergence, on the development of soybean under 'Cerrado' field, conditions. In the first year, after the soybean field was installed, Eleusine coracana became the major weed species in the finger millet plot. Because this species was not controlled by herbicides, its presence negatively influenced soybean development. The herbicide imazaquin indirectly affected soybean plants, due to its inefficient weed control. Soybean plants grown under St. Lucia Grass (both years) and finger millet (second year) reached

(1) Recebido para publicação em 25 de novembro de 2005 e aceito em 29 de junho de 2006.

$\left({ }^{2}\right)$ Departamento de Fitossanidade, Universidade Estadual Paulista (UNESP), Via de Acesso Prof. Paulo Donato Castellane, s/n., 14884-900 Jaboticabal (SP). Brasil. E-mail: correianm@fcav.unesp.br. *Autora correspondente. jcdurigan@fcav.unesp.br 
higher grain yield, mass accumulation and height. Sorghum residues affected soybean development in both years. The amount of residues, had difference between them for forage millet (first year) and sorghum (second year). The small amounts of forage millet and major of sorghum caused injury in soybean plants.

Key words: cerrado, mulch, chemical control, integrated management, weed, no-tillage system.

\section{INTRODUÇÃO}

A região, originalmente sob vegetação de cerrado, possui solos ácidos e pobres quimicamente. Mesmo assim, está com expansão agrícola acelerada da cultura de soja. Em grande parte das áreas agrícolas daquela região, a preocupação do cultivo restringe-se apenas ao enriquecimento químico do solo, a fim de suprir as exigências nutricionais da cultura e atingir produtividade elevada em curto prazo. Em contrapartida, tem-se o sistema de semeadura direta, somando esforços para uma atividade agrícola mais racional e menos exploratória. Estima-se que ao redor de 22 milhões de hectares sejam, anualmente, cultivados nesse sistema, seis milhões apenas na região de cerrado (FEDERAÇão Brasileira De Plantio Direto Na Palha, 2005).

No entanto, a cobertura morta mantida sobre o solo no sistema de semeadura direta pode prejudicar o estabelecimento de culturas sensíveis a ela. Os efeitos deletérios podem estar relacionados a fenômenos alelopáticos, pela liberação de substâncias orgânicas, denominadas aleloquímicos, durante o processo de decomposição dos resíduos. Fatores inerentes ao solo também devem ser considerados, como imobilização do nitrogênio mineral pelos microrganismos do solo, resultando no esgotamento temporário deste nutriente no solo. Embora, posteriormente, com o declínio da população microbiana, os níveis de nitrogênio sejam restabelecidos. Todavia, o desenvolvimento inicial da cultura e, em alguns casos até estádios mais avançados, fica comprometido. Em condições de campo, é difícil separar ou atribuir os efeitos observados a único processo, ocorrendo interações entre eles.

A esse respeito, constatou-se que a palha de sorgo incorporada ao solo atrasou o desenvolvimento do trigo em sucessão, mas não afetou a produtividade de grãos da cultura (Roth et al., 2000). Quando mantida na superfície do solo, sem incorporação, apesar de pouco afetar o estande de plantas, reduziu a produtividade de grãos de trigo. Os resultados foram dependentes, em grande parte, do grau de decomposição da palha antes da semeadura da cultura do trigo. A incorporação ao solo ou a trituração dos resíduos acelera sua decomposição, reduzindo o potencial inibitório do sorgo sobre o trigo em sucessão (ROTH et al., 2000).
Resíduos de milheto comum, incorporados ao solo ou mantidos na sua superfície, não interferiram no desenvolvimento da cultura da soja em sucessão. A quantidade de matéria seca produzida foi de 11 e $16 \mathrm{t} \mathrm{ha}^{-1}$, respectivamente, no primeiro e segundo anos do trabalho (CARVALHO et al., 2004).

Nas plantas de soja crescidas sobre palha de aveia-branca, em relação às dos demais tratamentos, foram observadas menor altura e folhas com coloração verde menos intensa, recuperando-se, em parte, no fim do ciclo (SANTOS et al., 1991). Os autores atribuíram tal efeito à quantidade elevada de resíduos de aveia e à sua decomposição mais lenta, pois poderia estar ocorrendo liberação de substâncias orgânicas, inibidoras do desenvolvimento da soja, durante o processo de decomposição. Entretanto, aspectos nutricionais também deveriam ser considerados, como deficiência de fósforo e nitrogênio, uma vez que, para decompor os materiais vegetais adicionados ao solo, os microrganismos imobilizam tais nutrientes, indisponibilizando-os temporariamente.

Os benefícios proporcionados pelo sistema de semeadura direta são incontestáveis ao solo, aos mananciais de água ou ao sistema produtivo como um todo. Contudo, algumas dúvidas ainda se fazem pertinentes e precisam ser esclarecidas, como o efeito da associação de resíduos vegetais, produzidos "in locu", ao uso de herbicidas, como diclosulam e imazaquin, no desenvolvimento da cultura da soja no sistema de semeadura direta.

O objetivo do presente trabalho foi avaliar, em condições de campo e na região originalmente sob cerrado, os efeitos dos tipos e das quantidades de resíduos vegetais produzidos "in locu", associados à herbicidas residuais, aplicados em pré-emergência, no desenvolvimento da cultura da soja no sistema de semeadura direta.

\section{MATERIAL E MÉTODOS}

O experimento foi desenvolvido durante o período de fevereiro de 2003 a março de 2004, e repetido de março de 2004 a março de 2005, na mesma área experimental, na Fazenda Três Marcos, localizada em Uberlândia (MG). A altitude do local é de, aproximadamente, 872 metros, latitude de $18^{\circ} 55^{\prime} \mathrm{S}$ e a longitude de $48^{\circ} 17^{\prime} \mathrm{W}$. Segundo a classificação de 
Köeppen, o clima da região é do tipo Aw (Geocities, 2006). O solo da área experimental é representativo da região, classificado como Latossolo VermelhoAmarelo distroférrico, textura argilosa. Originalmente, o solo esteve sob vegetação de cerrado, sendo submetido ao sistema de semeadura direta há quatro anos, com as culturas de milho/sorgo no inverno e soja / crotalária no verão.

O delineamento experimental utilizado foi o de blocos ao acaso, em esquema de parcelas subsubdivididas, com quatro repetições. Foram mantidos quatro tipos de cobertura nas parcelas: sorgo de cobertura (Sorghum bicolor x S. sudanensis 'Cober Exp'), milheto forrageiro (Pennisetum americanum 'BN2'), capim pé-de-galinha (Eleusine coracana) e capim braquiária (Brachiaria brizantha). Foram avaliadas duas quantidades de palha nas subparcelas: 3,0 e 5,5 tha- ${ }^{-1}$, no primeiro ano, e 3,5 e 5,8 tha- ${ }^{-1}$, no segundo. Nas subsubparcelas foram aplicados dois herbicidas: diclosulam $\left(35 \mathrm{~g} \mathrm{ha}^{-1}\right)$ e imazaquin $\left(140 \mathrm{~g} \mathrm{ha}^{-1}\right)$. Além disso, foram estabelecidas quatro testemunhas como tratamentos adicionais, sem restos culturais. Em duas delas foram aplicados os herbicidas,o diclosulam em uma e o imazaquin em outra. As outras duas testemunhas não foram tratadas com os herbicidas, sendo uma capinada até o fechamento da cultura, e a outra mantida infestada durante todo o ciclo da cultura.

As culturas de cobertura foram instaladas na última semana de fevereiro de 2003 e na primeira de março de 2004. Para a obtenção das duas quantidades de palha, variaram-se as densidades de semeadura de milheto forrageiro (10 e $15 \mathrm{~kg}$ ha ${ }^{1}$ ), capim pé-de-galinha (5 e $10 \mathrm{~kg} \mathrm{ha}^{-1}$ ) e capim braquiária $\left(4,5\right.$ e $\left.18 \mathrm{~kg} \mathrm{ha}^{-1}\right)$, todos semeados a lanço. O sorgo de cobertura foi semeado na quantidade de $15 \mathrm{~kg} \mathrm{ha}^{-1}$, a lanço ou em linha.

As sementes produzidas foram, juntamente com os outros resíduos vegetais, depositadas ao solo, com auxílio de uma roçadora, em julho de 2003. No ano seguinte, as plantas não foram cortadas, atingindo o solo apenas com a ação dos ventos ou de máquinas agrícolas, no momento da "dessecação" da cobertura vegetal e da semeadura da soja.

Na segunda quinzena de outubro, fez-se a dessecação da área experimental, utilizando-se, no primeiro ano, o herbicida glyphosate na dose de 1,44 $\mathrm{kg} \mathrm{ha}^{-1}$ de equivalente ácido e, no segundo, a mistura em tanque de $1,44 \mathrm{~kg} \mathrm{ha}^{-1}$ de equivalente ácido de glyphosate e $80 \mathrm{~g} \mathrm{ha}^{-1}$ de carfentrazone-ethyl. A mistura foi utilizada devido à ocorrência da planta daninha Commelina benghalensis, cujo controle pelo glyphosate é insatisfatório. No entanto, vale ressaltar que misturas em tanque de herbicidas são proibidas por lei no Brasil, não possuindo respaldo técnico. Após sete dias, as parcelas com capim braquiária foram novamente tratadas com glyphosate na mesma dose.

Devido à ausência de chuvas, não se verificaram fluxos de emergência de plantas daninhas, no intervalo entre a primeira e a segunda dessecação realizadas nas parcelas de capim braquiária que persistiu até a aplicação dos herbicidas residuais, 15 dias após a primeira dessecação.

Após a formação da cobertura morta, foi realizada uma amostragem em cada subparcela para quantificação do equivalente em palha por hectare. Dentro da área útil de cada subparcela foram coletados os resíduos vegetais, na área de $0,25 \mathrm{~m}^{2}$, em quatro pontos escolhidos aleatoriamente. A palha coletada foi cuidadosamente peneirada e limpa com o auxílio de um pincel, para se retirar as partículas de solo aderidas. As amostras foram acondicionadas em sacos de papel e encaminhadas ao laboratório para pesagem. Através de análise estatística, pelo teste de Tukey a $5 \%$ de probabilidade, constatou-se que dentro de cada nível de palha não havia diferença significativa entre os tipos de cobertura, com os valores de 3,0 e 5,5 $\mathrm{t} \mathrm{ha}^{-1}$, para menor e maior nível, no ano de $2003 / 2004$, e de 3,5 e 5,8 $\mathrm{tha}^{-1}$, no ano seguinte.

Com base em análises de solo, cujas amostras foram coletadas de 0 a $20 \mathrm{~cm}$ de profundidade para cada tratamento, e na necessidade nutricional da soja, fez-se a mesma adubação para todas as parcelas. Foram aplicados $300 \mathrm{~kg} \mathrm{ha}^{-1}$ do formulado 02-20-20 no sulco de semeadura, no primeiro ano, e $400 \mathrm{~kg} \mathrm{ha}^{-1}$ do mesmo formulado, em 2004/2005. Além disso, as sementes de soja foram submetidas à inoculação com $3 \mathrm{~mL}$ de Urulec-L kg${ }^{-1}$ de sementes em 2003/2004 e com $2 \mathrm{~g}$ de Biomax $\mathrm{kg}^{-1}$ de sementes no ano seguinte.

A soja (cv. M-SOY 6101) foi semeada em sistema de semeadura direta, na última semana de outubro de 2003 e na primeira de novembro em 2004, a uma profundidade de $5 \mathrm{~cm}$, com $0,5 \mathrm{~m}$ de distância entre as linhas e 23 sementes por metro em 2003/2004 e 26 sementes no em 2004/2005. Foram utilizadas semeadoras SEMEATO PAR 2800, de seis linhas, no primeiro ano, e SEMEATO SHM, de quatro linhas, no ano seguinte.

As parcelas (tipos de cobertura) tinham $6 \mathrm{~m}$ de largura e $10 \mathrm{~m}$ de comprimento. Dentro de cada parcela foram demarcadas as subparcelas (quantidades de palha), com $3 \mathrm{~m}$ de largura e $10 \mathrm{~m}$ de comprimento, onde foram delimitadas as subsubparcelas (herbicidas residuais), constituídas por seis linhas de soja com $5 \mathrm{~m}$ de comprimento, com quatro linhas centrais de $4 \mathrm{~m}$ de comprimento como área útil, totalizando $8 \mathrm{~m}^{2}$. 
Os herbicidas diclosulam e imazaquin foram aplicados em pré-emergência, no dia seguinte à semeadura da soja, com pulverizador costal, à pressão constante (mantida pelo $\mathrm{CO}_{2}$ comprimido) de 2,24 kgf $\mathrm{cm}^{-2}$, munido de barra com seis bicos de jato plano (leque) 110.02, espaçados de $0,5 \mathrm{~m}$, com consumo de calda equivalente a $200 \mathrm{~L} \mathrm{ha}^{-1}$. Os valores das temperaturas do ar e do solo, da umidade relativa do ar e as condições de vento, no momento das aplicações, estão na tabela 1.

Foram realizadas avaliações visuais dos sintomas de intoxicação nas plantas de soja, aos 14 e 28 dias após a aplicação (DAA) dos herbicidas no primeiro ano e aos 11, 20 e 32 DAA no segundo, atribuindo-se, para cada unidade experimental, nota média de dois avaliadores, em percentagem. Adotouse zero, para nenhuma injúria, e 100\% como morte total das plantas.

Determinou-se a altura das plantas de soja $(\mathrm{cm})$, considerando-se a distância entre o colo e a extremidade da haste principal. Essas avaliações foram feitas aos 35 e 120 DAA (momento da colheita dos grãos) em 2003/2004 e aos 32 e 110 DAA no ano seguinte. Aos 56 e 60 DAA, respectivamente, no primeiro e segundo anos, fez-se a quantificação da matéria seca da parte aérea das plantas de soja ( $\mathrm{g}$ planta $\left.^{-1}\right)$. Esses valores foram tomados de dez plantas coletadas em linha na área útil da sub-subparcela.

Para obtenção da produtividade de grãos por sub-subparcela, foram colhidas, manualmente, três linhas com 4 metros de comprimento, sendo, posteriormente, trilhadas e a umidade dos grãos corrigida para $13 \%$. Avaliou-se, ainda, a massa de cem grãos, escolhidos na produção da cada subsubparcela.

Os resultados foram submetidos ao teste $\mathrm{F}$ da análise de variância. Os efeitos dos tipos de cobertura, níveis e herbicidas, quando significativos, foram comparados pelo teste de Tukey a 5\% de probabilidade. Para avaliar o comportamento dos quatro tratamentos sem palha em relação às coberturas, aos níveis de palha e aos herbicidas residuais, os graus de liberdade de tratamentos foram desdobrados segundo um esquema de contrastes ortogonais de interesse. As testemunhas foram comparadas entre si e aos tratamentos com palha convenientes. Aplicou-se o teste F para cada contraste, aceitando-se ou rejeitando-se a hipótese $\mathrm{H}_{0}(\mathrm{Y}=0)$.

\section{RESULTADOS E DISCUSSÃO}

No primeiro ano, a interação tipos de cobertura $x$ níveis $x$ herbicidas foi significativa apenas para matéria seca de plantas e produtividade de grãos, observando-se comportamento diferenciado e dependente entre os fatores. Optou-se, neste caso, pelo desdobramento das combinações entre tipos e níveis de cobertura para cada herbicida estudado. A interação tipos $x$ níveis foi significativa para fitointoxicação, aos 14 e 28 dias após a aplicação (DAA) dos herbicidas, e altura de plantas nas duas épocas avaliadas. A interação tipos $\mathrm{x}$ herbicidas também influenciou na altura das plantas no momento da colheita. Para massa de cem grãos, nenhuma das interações foi significativa, com efeito significativo apenas dos herbicidas.

Os resultados do segundo ano agrícola de 2004/2005 foram mais efetivos e consolidaram algumas informações relatadas no primeiro ano. Pelas análises de variância, constatou-se que a interação tipos de cobertura $x$ níveis $x$ herbicidas foi significativa apenas para altura de plantas aos 110 DAA. A interação níveis $x$ herbicidas, além dos efeitos isolados de tipos e níveis de cobertura, foi significativa para a matéria seca de plantas. As coberturas influenciaram na altura de plantas aos 32 DAA, na massa de cem grãos e na produtividade de grãos. A interação tipos $x$ níveis também foi significativa para a produtividade de grãos.

Tabela 1. Temperaturas do ar e do solo, umidade relativa do ar e condições de vento, no momento das aplicações dos herbicidas. Uberlândia (MG), 2003/2004 e 2004/2005

\begin{tabular}{|c|c|c|c|c|}
\hline \multirow{2}{*}{ Ano agrícola } & \multicolumn{2}{|c|}{ Temperatura } & \multirow{2}{*}{ Umidade relativa do ar } & \multirow{2}{*}{ Condições de vento } \\
\hline & $\mathrm{Ar}$ & Solo & & \\
\hline & & 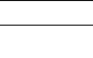 & $\%$ & \\
\hline $2003 / 2004$ & 29 & 26,4 & 51 & Brisa suave \\
\hline $2004 / 2005$ & 27 & 25,2 & 59 & Brisa suave \\
\hline
\end{tabular}


Tabela 2. Percentagem de intoxicação nas plantas de soja aos 14 e 28 dias após a aplicação (DAA) dos herbicidas diclosulam e imazaquin, em pré-emergência, sobre quatro tipos de cobertura e dois níveis de palha, além das testemunhas (sem palha). Uberlândia (MG), 2003/2004

\begin{tabular}{|c|c|c|c|c|}
\hline \multirow{3}{*}{ Tipos de cobertura } & \multicolumn{4}{|c|}{ Níveis de palha $\left(\mathrm{t} \mathrm{ha}^{-1}\right)$} \\
\hline & 3,0 & 5,5 & 3,0 & 5,5 \\
\hline & \multicolumn{2}{|c|}{14 DAA } & \multicolumn{2}{|c|}{$28 \mathrm{DAA}$} \\
\hline & & $x_{1}$ & & \\
\hline Sorgo & $7,25 \mathrm{~b} \quad \mathrm{~B}$ & $12,88 \mathrm{~b} \quad \mathrm{~A}$ & 5,63 a $B$ & 41,25 a $\mathrm{A}$ \\
\hline Milheto forrageiro & $9,75 \mathrm{~b} \quad \mathrm{~A}$ & $11,63 \mathrm{~b} \quad \mathrm{~A}$ & 6,63 a $A$ & $7,88 \mathrm{c} \mathrm{A}$ \\
\hline Capim pé-de-galinha & $11,00 \mathrm{~b} \quad \mathrm{~A}$ & $4,50 \mathrm{~b} \quad \mathrm{~B}$ & 13,50 a $\mathrm{A}$ & $17,88 \mathrm{~b} \quad \mathrm{~A}$ \\
\hline Capim braquiária & 34,88 a B & 46,25 a $\mathrm{A}$ & 11,25 a $B$ & 35,00 a $\mathrm{A}$ \\
\hline DMS (na linha) & \multicolumn{2}{|c|}{5,45} & \multicolumn{2}{|c|}{7,64} \\
\hline DMS (na coluna) & \multicolumn{2}{|c|}{11,65} & \multicolumn{2}{|c|}{8,30} \\
\hline Test. s/ palha trat. c/ herb. $1\left({ }^{1}\right)$ & \multicolumn{2}{|c|}{15,00} & \multicolumn{2}{|c|}{3,75} \\
\hline Test. s/ palha trat. c/ herb. $2\left({ }^{2}\right)$ & \multicolumn{2}{|c|}{8,75} & \multicolumn{2}{|c|}{7,50} \\
\hline Test. s/ palha e capinada $\left({ }^{3}\right)$ & \multicolumn{2}{|c|}{0,00} & \multicolumn{2}{|c|}{0,00} \\
\hline Test. s/ palha $\left({ }^{4}\right)$ & \multicolumn{2}{|c|}{0,00} & \multicolumn{2}{|c|}{0,00} \\
\hline
\end{tabular}

Com base no teste de Tukey a 5\% de probabilidade, médias seguidas de letra minúscula, nas colunas, comparam tipos de cobertura dentro de cada nível de palha e, letras maiúsculas, nas linhas, comparam os dois níveis para cada cobertura. $\left({ }^{1}\right)$ Testemunha sem palha e tratada com o herbicida diclosulam. $\left({ }^{2}\right)$ Testemunha sem palha e tratada com o herbicida imazaquin. $\left({ }^{3}\right)$ Testemunha sem palha e capinada. $\left({ }^{4}\right)$ Testemunha sem palha e mantida infestada.

No ano agrícola 2003/2004, nas plantas de soja, inicialmente,constatou-se maior intoxicação quando crescidas sobre os dois níveis de palha de capim braquiária. Com o passar do tempo, aos 28 DAA, nas plantas sobre o maior nível de palha de sorgo, também houve sintomas visíveis de intoxicação, não diferindo daquelas sobre capim braquiária. No menor nível, não houve diferença significativa entre as coberturas (Tabela 2). Os sintomas observados foram clorose, principalmente nas folhas jovens, e redução do porte das plantas.

Por meio de análises por contrastes, observouse, aos 14 DAA, que as testemunhas não tratadas com os herbicidas (a mantida infestada e a capinada) diferiram das testemunhas tratadas $\left(\mathrm{F}_{\mathrm{c}}=18,35^{* *}\right)$ e, também, das coberturas estudadas $\left(\mathrm{F}_{\mathrm{c}}=56,48^{* *}\right)$, com exceção do maior nível de capim pé-de-galinha $\left(F_{c}=1,76\right)$. As testemunhas tratadas com os herbicidas não diferiram entre si $\left(F_{c}=2,54\right)$, e apresentaram plantas de soja com intoxicação similar às plantas dos dois níveis de palha de sorgo $\left(\mathrm{F}_{\mathrm{c}}=2,49\right)$ e milheto forrageiro $\left(\mathrm{F}_{\mathrm{c}}=0,43\right)$ e do menor nível de capim pé-degalinha $\left(\mathrm{F}_{\mathrm{c}}=0,07\right)$. Aos $28 \mathrm{DAA}$, verificou-se que não houve diferença significativa entre as testemunhas não tratadas e a que recebeu o diclosulam $\left(\mathrm{F}_{\mathrm{c}}=2,66\right)$, porém, as mesmas diferiram da testemunha tratada com imazaquin $\left(\mathrm{F}_{\mathrm{c}}=10,65^{* *}\right)$. Nessa, as plantas de soja tiveram menor intoxicação comparadas às plantas dos dois níveis de capim pé-de-galinha $\left(\mathrm{F}_{\mathrm{c}}=12,69^{* *}\right)$ e às plantas dos maiores níveis de sorgo $\left(\mathrm{F}_{\mathrm{c}}=161,75^{* *}\right)$ e capim braquiária $\left(\mathrm{F}_{\mathrm{c}}=107,39^{* *}\right)$.

No segundo ano, as coberturas, nos seus dois níveis de palha, assim como os herbicidas estudados, não provocaram nenhum efeito fitotóxico visual nas plantas de soja, aos 11, 20 e 32 DAA.

Quanto à altura das plantas, no primeiro ano, aos 35 DAA (Tabela 3), houve menor média sobre o maior nível de cobertura de sorgo, diferindo significativamente das demais coberturas. No menor nível, as palhas de sorgo e milheto forrageiro não diferiram entre si, resultando nas menores médias. Por contrastes, verificou-se que não houve efeito significativo entre as testemunhas não tratadas com herbicidas e a que recebeu diclosulam $\left(\mathrm{F}_{\mathrm{c}}=0,49\right)$. No entanto, diferiram da testemunha tratada com imazaquin $\left(\mathrm{F}_{\mathrm{c}}=7,59^{* *}\right)$. As testemunhas sem palha diferiram apenas dois níveis de palha de sorgo $\left(\mathrm{F}_{\mathrm{c}}=76,50^{* *}\right)$ e do menor nível de milheto forrageiro $\left(\mathrm{F}_{\mathrm{c}}=14,59^{* *}\right)$, com valores inferiores. 
Tabela 3. Altura das plantas de soja (cm) aos 35 e 120 dias após a aplicação (DAA) dos herbicidas diclosulam e imazaquin, em préemergência, sobre quatro tipos de cobertura e dois níveis de palha, além das testemunhas (sem palha). Uberlândia (MG), $2003 / 2004$

\begin{tabular}{|c|c|c|c|c|}
\hline \multirow{3}{*}{ Tipos de cobertura } & \multicolumn{4}{|c|}{ Níveis de palha $\left(\mathrm{t} \mathrm{ha}^{-1}\right)$} \\
\hline & 3,0 & 5,5 & 3,0 & 5,5 \\
\hline & \multicolumn{2}{|c|}{35 DAA } & \multicolumn{2}{|c|}{120 DAA } \\
\hline Sorgo & $16,38 \mathrm{~b} \quad \mathrm{~A}$ & $14,31 \mathrm{~b} \quad \mathrm{~B}$ & $57,67 \mathrm{~b} \quad$ B & $65,16 \mathrm{~b} \quad \mathrm{~A}$ \\
\hline Milheto-forrageiro & $16,99 \mathrm{~b} \quad \mathrm{~B}$ & 18,80 a $\mathrm{A}$ & 83,34 a $A$ & 76,91 a $B$ \\
\hline Capim-pé-de-galinha & 19,58 a $A$ & 19,28 a $A$ & $65,15 \mathrm{~b} \quad \mathrm{~A}$ & $68,97 \mathrm{ab} \mathrm{A}$ \\
\hline Capim-braquiária & 19,23 a $\mathrm{A}$ & 19,90 a $\mathrm{A}$ & 79,00 a $\mathrm{A}$ & 74,45 a $\mathrm{A}$ \\
\hline DMS (na linha) & \multicolumn{2}{|c|}{1,30} & \multicolumn{2}{|c|}{6,00} \\
\hline DMS (na coluna) & \multicolumn{2}{|c|}{1,57} & \multicolumn{2}{|c|}{8,27} \\
\hline Test. s/ palha trat. c/ herb1. ${ }^{(1)}$ & \multicolumn{2}{|c|}{19,00} & \multicolumn{2}{|c|}{76,00} \\
\hline Test. s/ palha trat. c/ herb2. ${ }^{(2)}$ & \multicolumn{2}{|c|}{20,30} & \multicolumn{2}{|c|}{62,68} \\
\hline Test. s/ palha e capinada ${ }^{(3)}$ & \multicolumn{2}{|c|}{18,50} & \multicolumn{2}{|c|}{75,45} \\
\hline Test. s/ palha ${ }^{(4)}$ & \multicolumn{2}{|c|}{18,65} & \multicolumn{2}{|c|}{71,59} \\
\hline
\end{tabular}

Com base no teste de Tukey a 5\% de probabilidade, médias seguidas de letra minúscula, nas colunas, comparam tipos de cobertura dentro de cada nível de palha e, letras maiúsculas, nas linhas, comparam os dois níveis para cada cobertura. $\left({ }^{1}\right)$ Testemunha sem palha e tratada com o herbicida diclosulam. $\left({ }^{2}\right)$ Testemunha sem palha e tratada com o herbicida imazaquin. $\left({ }^{3}\right)$ Testemunha sem palha e capinada. $\left({ }^{4}\right)$ Testemunha sem palha e mantida infestada.

Em avaliação posterior, aos 120 DAA (Tabela 3), nos dois níveis, as coberturas de sorgo e capim péde-galinha promoveram menor altura de plantas de soja. Por meio de comparação por contrastes, não se constatou diferença significativa entre as testemunhas que não receberam herbicidas (a mantida infestada e a capinada) e a tratada com diclosulam $\left(\mathrm{F}_{\mathrm{c}}=0,72\right)$. Nessas condições, observaram-se médias superiores à da testemunha tratada com imazaquin $\left(\mathrm{F}_{\mathrm{c}}=23,39^{* *}\right)$ e à cobertura de sorgo $\left(\mathrm{F}_{\mathrm{c}}=41,68^{* *}\right)$ nos seus dois níveis de palha.

Pelos resultados relatados anteriormente, verificou-se o efeito das plantas daninhas no desenvolvimento da soja, visto que houve controle ineficaz dessas sobre cobertura de capim pé-degalinha, refletindo na altura final das plantas de soja, principalmente para o herbicida imazaquin, com o qual o controle foi nulo. As plantas de Eleusine coracana produziram sementes, que foram depositadas ao solo com o manejo da cultura. Com o início do período chuvoso, houve um fluxo de emergência e suas plântulas foram eliminadas com a dessecação. Contudo, novos fluxos de emergência foram constatados após a semeadura da soja, infestando a cultura. O herbicida imazaquin não controla nem suprime essa gramínea e, apesar do efeito supressor do diclosulam, não foi suficiente para alcançar controle. Dessa forma, tornou-se a planta daninha mais problemática sobre sua própria cobertura.
Na cobertura de sorgo, houve controle satisfatório das plantas daninhas para ambos os herbicidas, provavelmente os resultados na cultura da soja sejam decorrentes de efeitos químicos desse resíduo. Esses efeitos estão relacionados com alelopatia, imobilização e reciclagem de nutrientes e alterações na relação carbono nitrogênio $(C / N)$. Os fenômenos alelopáticos estão envolvidos com a liberação de substâncias químicas que podem inibir a germinação e o desenvolvimento de algumas espécies de plantas cultivadas e daninhas. Para RicE (1984), essas substâncias orgânicas (aleloquímicos) estão implicadas em grande diversidade de efeitos nas plantas, que incluem atraso ou inibição completa da germinação de sementes, crescimento paralisado, injúria no sistema radicular, clorose, murcha e morte das plantas. A liberação desses compostos no agroecossistema pode ocorrer por lixiviação, ocasionada pela chuva ou orvalho, por tecidos vegetais em decomposição, por volatilização de substâncias provenientes de plantas em estado vegetativo e por exsudação do sistema radicular.

Também se deve considerar que a adição de material vegetal no solo com alta relação $C / N$, como a palha de sorgo, resulta em maior atividade microbiana, o que condiciona imobilização do nitrogênio e fósforo do solo. Assim, respostas de crescimento, após a adição de resíduos vegetais, podem ser atribuídas ao esgotamento de nitrogênio e 
fósforo do solo e não a moléculas orgânicas (INDERJIT e Keating, 1999). Os sintomas de deficiência de fósforo são, além do empobrecimento do sistema radicular, uma nítida interferência no desenvolvimento da parte aérea das plantas de soja. Quanto ao nitrogênio, sua imobilização interfere no estabelecimento inicial da soja, com conseqüências no seu porte (PASQUALETTO, 1999).

No trabalho desenvolvido por PAsQualetto (1999), a palha de sorgo não afetou a altura das plantas, a massa de cem grãos e a produtividade de grãos de soja (cv. EMGOPA 309). Em sucessão ao sorgo houve maior acúmulo de matéria seca das plantas de soja . No entanto, Peixoto e Souza (2002) relataram que a palha de sorgo interferiu na altura das plantas de soja (cv. Garimpo), desde as fases iniciais até a fase de pré-colheita, havendo decréscimo na produtividade de grãos com o aumento dos resíduos em cobertura. Esses resultados contrariaram os dados de CORREIA et al. (2002), em que a palha de três híbridos de sorgo (DK 860, SARA e AMBAR), cultivados no outono/ inverno, não interferiu na altura das plantas, na matéria seca da parte aérea e na produtividade de grãos de soja, cv. MG/BR 46 (Conquista). Todavia, as palhas dos híbridos SARA e AMBAR causaram redução no porte das plantas de soja até 40 dias após sua emergência.

No ano agrícola 2004/2005, aos 32 DAA, verificou-se que as plantas de soja tinham menor altura sobre palha de sorgo, diferindo significativamente de capim braquiária e capim pé-de-galinha (Tabela 4). Mediante a comparação por contrastes, não se verificaram diferenças significativas entre as testemunhas tratadas com os herbicidas e a mantida infestada $\left(\mathrm{F}_{\mathrm{c}}=0,52\right)$, as quais diferiram apenas da cobertura de sorgo $\left(\mathrm{F}_{\mathrm{c}}=10,21^{* *}\right)$ e da testemunha capinada $\left(\mathrm{F}_{\mathrm{c}}=9,12^{* *}\right)$, que não diferiram entre si $\left(\mathrm{F}_{\mathrm{c}}=0,02\right)$.

No fim do ciclo da cultura (Tabela 5), observou-se, no maior nível de palha, menor altura das plantas de soja sobre a cobertura de sorgo, diferindo significativamente das outras coberturas. No menor nível, quando aplicado diclosulam, as palhas de sorgo e milheto forrageiro resultaram nas menores médias. Contudo, para imazaquin, não houve diferença significativa entre as coberturas nos seus menores níveis. Por contrastes, para ambos os herbicidas, não foi observada diferença significativa entre as testemunhas sem palha $\left(\mathrm{F}_{\mathrm{c}}=3,12\right.$ e 0,35$)$, que diferiram apenas da cobertura de sorgo $\left(\mathrm{F}_{\mathrm{c}}=57,89^{*} \mathrm{e}\right.$ $88,76^{* *}$ ) no seu maior nível.

As plantas de soja sobre cobertura de sorgo não conseguiram recuperar o crescimento com o decorrer do tempo, permanecendo com as menores médias, resultado possivelmente justificado pelos efeitos químicos da palha de sorgo, discutido anteriormente. No entanto, não se pode afirmar qual dos fenômenos estaria envolvido, se alelopatia ou fatores nutricionais, entre outros. Esses dados corroboram os obtidos no primeiro ano do experimento.

Tabela 4. Altura das plantas de soja aos 32 dias após a aplicação (DAA) dos herbicidas diclosulam e imazaquin, em préemergência, sobre quatro tipos de cobertura, além das testemunhas (sem palha). Uberlândia (MG), 2004/2005

\begin{tabular}{lc}
\hline Tipos de cobertura & 32 DAA \\
\hline Sorgo & $17,86 \mathrm{~b}$ \\
Milheto-forrageiro & $19,29 \mathrm{ab}$ \\
Capim-pé-de-galinha & $20,23 \mathrm{a}$ \\
Capim-braquiária & $20,02 \mathrm{a}$ \\
\hline DMS & 1,74 \\
Testemunha sem palha e tratada com diclosulam & 20,90 \\
Testemunha sem palha e tratada com imazaquin & 19,83 \\
Testemunha sem palha e capinada & 18,00 \\
Testemunha sem palha e mantida infestada & 19,80 \\
\hline
\end{tabular}

Médias seguidas pela mesma letra não diferem significativamente entre si pelo teste de Tukey a 5\% de probabilidade. 
Tabela 5. Altura das plantas de soja aos 110 dias após a aplicação (DAA) dos herbicidas diclosulam e imazaquin, em préemergência, sobre quatro tipos de cobertura e dois níveis de palha, além das testemunhas (sem palha). Uberlândia - MG, $2004 / 2005$

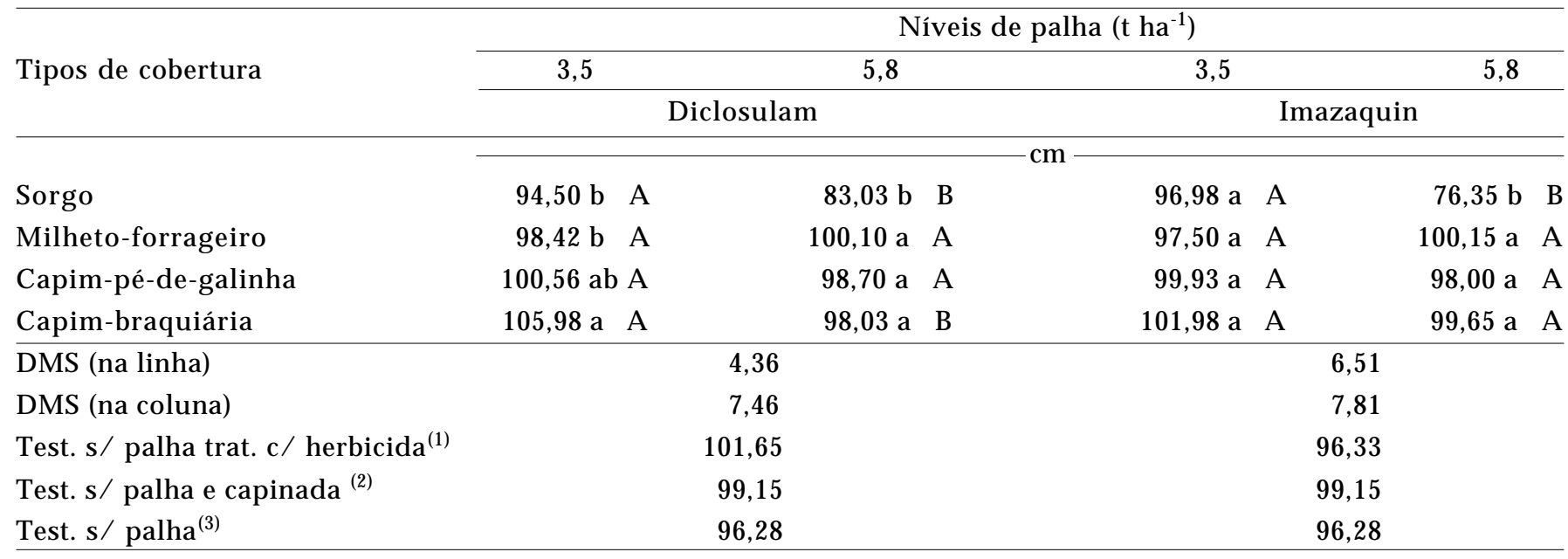

Com base no teste de Tukey a 5\% de probabilidade, médias seguidas de letra minúscula, nas colunas, comparam tipos de cobertura dentro de cada nível de palha e, letras maiúsculas, nas linhas, comparam os dois níveis para cada cobertura. ( ${ }^{1}$ ) Testemunha sem palha e tratada com os herbicidas. $\left({ }^{2}\right)$ Testemunha sem palha e capinada. ( $\left(^{3}\right)$ Testemunha sem palha e mantida infestada.

No primeiro ano, para ambos os herbicidas estudados, houve menor matéria seca de plantas de soja crescidas sobre as palhas de sorgo e capim péde-galinha, nos dois níveis estudados (Tabela 6). Foi constatado, também, maior influência dos níveis de palha quando aplicado o diclosulam, comparado ao imazaquin. Por contrastes, verificou-se, nas parcelas que receberam o diclosulam, que a testemunha tratada com o herbicida e a capinada não diferiram entre si $\left(\mathrm{F}_{\mathrm{c}}=0,56\right)$, porém, diferiram da testemunha mantida infestada $\left(\mathrm{F}_{\mathrm{c}}=141,03^{* *}\right)$, que não diferiu dos maiores níveis de palha de sorgo $\left(\mathrm{F}_{\mathrm{c}}=0,00\right)$ e capim pé-degalinha $\left(F_{c}=0,13\right)$. Não houve diferença significativa entre as testemunhas sem palha (a tratada e a capinada) e o maior nível de palha de milheto forrageiro $\left(F_{c}=0,01\right)$. Quanto ao herbicida imazaquin, as testemunhas tratadas com o herbicida e a capinada diferiram entre si $\left(F_{c}=16,55^{* *}\right)$, com maior média para a capinada, que não diferiu do menor nível de palha de milheto forrageiro $\left(F_{c}=0,00\right)$. $O$ acúmulo de massa das plantas da testemunha tratada com imazaquin foi maior que o dos dois níveis de sorgo $\left(F_{c}=24,23^{* *}\right)$ e capim pé-de-galinha $\left(\mathrm{F}_{\mathrm{c}}=16,39^{* *}\right)$ e o da testemunha mantida infestada $\left(\mathrm{F}_{\mathrm{c}}=26,33^{* *}\right)$.

Os resultados no segundo ano foram mais efetivos e consolidaram algumas informações relatadas no primeiro. Em 2004/2005, houve controle satisfatório das plantas de Eleusine coracana no tratamento de capim pé-de-galinha, favorecendo uma convivência sem prejuízos para as plantas de soja. Esse processo foi de grande importância, pois no primeiro ano os dados de desenvolvimento da cultura, para esse tratamento, foram "mascarados" pelos efeitos deletérios desta espécie.

Nesse período, constatou-se nas plantas crescidas sobre palha de sorgo e milheto forrageiro menor acúmulo de matéria seca, diferindo significativamente de capim braquiária (Tabela 7). Por contrastes, não se verificaram diferenças significativas entre as testemunhas tratadas com os herbicidas e a capinada $\left(\mathrm{F}_{\mathrm{c}}=2,89\right)$. Entretanto, diferiram da testemunha mantida infestada $\left(\mathrm{F}_{\mathrm{c}}=11,18^{* *}\right)$, a qual resultou em plantas com acúmulo de massa estatisticamente similar às das coberturas de sorgo $\left(F_{c}=1,83\right)$ e milheto forrageiro $\left(F_{c}=3,64\right)$. Quanto aos níveis de palha, a testemunha mantida infestada não diferiu do maior nível $\left(F_{c}=3,56\right)$. Além disso, não houve diferença significativa entre as demais testemunhas e o menor nível de palha $\left(\mathrm{F}_{\mathrm{c}}=0,18\right)$.

No ano agrícola 2003/2004, os herbicidas influenciaram significativamente na massa de cem grãos, observando-se maior média com a aplicação de diclosulam (dados não mostrados). Esse resultado decorre do melhor controle das plantas daninhas por esse herbicida, o que beneficiou indiretamente as plantas de soja, especificamente na massa de grãos. 
No ano seguinte, embora o teste $\mathrm{F}$, ao nível de $5 \%$, tenha detectado influência significativa das coberturas na massa de cem grãos, aplicando-se o teste de Tukey, no mesmo nível de significância, não se verificou diferença entre elas (Tabela 8). Pelas análises por contrastes, observou-se que não houve diferença significativa entre a testemunha mantida infestada e a palha de sorgo $\left(\mathrm{F}_{\mathrm{c}}=2,81\right)$, as quais resultaram nas menores médias. As demais testemunhas sem palha não diferiram entre si $\left(F_{c}=0,01\right.$ e 1,22) e, também, não diferiram das coberturas de milheto forrageiro $\left(F_{c}=0,53\right)$, capim braquiária $\left(\mathrm{F}_{\mathrm{c}}=0,27\right)$ e capim pé-de-galinha $\left(\mathrm{F}_{\mathrm{c}}=1,94\right)$.

Tabela 6. Matéria seca da parte aérea de plantas de soja aos 56 dias após a aplicação (DAA) dos herbicidas diclosulam e imazaquin, em pré-emergência, sobre quatro tipos de palha e dois níveis de cobertura, além das testemunhas (sem palha). Uberlândia - MG, 2003/2004

\begin{tabular}{|c|c|c|c|c|}
\hline \multirow{3}{*}{ Tipos de cobertura } & \multicolumn{4}{|c|}{ Níveis de palha ( $\mathrm{t} \mathrm{ha}^{-1}$ ) } \\
\hline & 3,0 & 5,5 & 3,0 & 5,5 \\
\hline & \multicolumn{2}{|c|}{ Diclosulam } & \multicolumn{2}{|c|}{ Imazaquin } \\
\hline & & +2 & & \\
\hline Sorgo & $7,61 \mathrm{ab} A$ & 4,03 с $B$ & $4,71 \mathrm{~b} \quad \mathrm{~A}$ & $4,89 \mathrm{c} \quad \mathrm{A}$ \\
\hline Milheto-forrageiro & 8,55 a $\mathrm{B}$ & 12,55 a $A$ & 12,05 a $\mathrm{A}$ & 8,01 a $B$ \\
\hline Capim-pé-de-galinha & $6,43 \mathrm{~b} \quad \mathrm{~A}$ & $4,34 \mathrm{c} \quad \mathrm{B}$ & $5,47 \mathrm{~b} \quad \mathrm{~A}$ & 5,46 bc A \\
\hline Capim-braquiária & 8,53 a $\mathrm{A}$ & $9,56 \mathrm{~b} \quad \mathrm{~A}$ & 9,69 a $\mathrm{A}$ & $7,87 \mathrm{ab} \mathrm{A}$ \\
\hline DMS (na linha) & \multicolumn{2}{|c|}{1,43} & \multicolumn{2}{|c|}{2,07} \\
\hline DMS (na coluna) & \multicolumn{2}{|c|}{1,68} & \multicolumn{2}{|c|}{2,51} \\
\hline Test. s/ palha trat. c/ herb..$^{(1)}$ & \multicolumn{2}{|c|}{12,86} & \multicolumn{2}{|c|}{8,54} \\
\hline Test. s/ palha e capinada ${ }^{(2)}$ & \multicolumn{2}{|c|}{12,09} & \multicolumn{2}{|c|}{12,09} \\
\hline Test. s/ palha ${ }^{(3)}$ & \multicolumn{2}{|c|}{4,04} & \multicolumn{2}{|c|}{4,04} \\
\hline
\end{tabular}

Com base no teste de Tukey a 5\% de probabilidade, médias seguidas de letra minúscula, nas colunas, comparam tipos de cobertura dentro de cada nível de palha e, letras maiúsculas, nas linhas, comparam os dois níveis para cada tcobertura. ( $\left.{ }^{1}\right)$ Testemunha sem palha e tratada com os herbicidas. ( $\left.{ }^{2}\right)$ Testemunha sem palha e capinada. ( ${ }^{3}$ ) Testemunha sem palha e mantida infestada.

Tabela 7. Matéria seca da parte aérea de plantas de soja ( $\mathrm{g}$ planta ${ }^{-1}$ ) aos 60 dias após a aplicação (DAA) dos herbicidas diclosulam e imazaquin, em pré-emergência, sobre quatro tipos de cobertura, além das testemunhas (sem palha). Uberlândia - MG, $2004 / 2005$

Tipos de cobertura Matéria seca

Sorgo g planta ${ }^{-1}$

Milheto-forrageiro

$7,55 \mathrm{~b}$

Capim-pé-de-galinha

Capim-braquiária

$9,24 \mathrm{ab}$

DMS

$10,40 \mathrm{a}$

Testemunha sem palha e tratada com diclosulam

2,13

Testemunha sem palha e tratada com imazaquin

9,23

Testemunha sem palha e capinada

9,45

Testemunha sem palha e mantida infestada

Médias seguidas pela mesma letra não diferem significativamente entre si pelo teste de Tukey a 5\% de probabilidade. 
Tabela 8. Massa de grãos de soja crescida sobre quatro tipos de cobertura, além das testemunhas (sem palha). Uberlândia - MG, $2004 / 2005$

Tipos de cobertura Peso de 100 sementes $\mathrm{g}$

Sorgo

$16,73 \mathrm{a}$

Milheto-forrageiro

$18,82 \mathrm{a}$

Capim-pé-de-galinha

18,46 a

Capim-braquiária

\section{DMS}

2,27

Testemunha sem palha e tratada com diclosulam

Testemunha sem palha e tratada com imazaquin

Testemunha sem palha e capinada

Testemunha sem palha e mantida infestada

Médias seguidas pela mesma letra não diferem significativamente entre si pelo teste de Tukey a 5\% de probabilidade.

Tabela 9. Produtividade de grãos () de soja crescida sobre quatro tipos de cobertura e dois níveis de palha, tratada com os herbicidas diclosulam e imazaquin, aplicados em pré-emergência, além das testemunhas (sem palha). Uberlândia (MG), $2003 / 2004$

\begin{tabular}{|c|c|c|c|c|}
\hline \multirow[b]{2}{*}{ Tipos de cobertura } & \multicolumn{4}{|c|}{ Níveis de palha $\left(\mathrm{t} \mathrm{ha}^{-1}\right)$} \\
\hline & 3,0 & 5,5 & 3,0 & 5,5 \\
\hline & \multicolumn{2}{|c|}{ Diclosulam } & \multicolumn{2}{|c|}{ Imazaquin } \\
\hline & \multicolumn{4}{|c|}{$-\mathrm{kg} \mathrm{ha}{ }^{-1}$} \\
\hline Sorgo & 2385,00 a $\mathrm{A}$ & $2167,50 \mathrm{ab} A$ & 1958,75 a $A$ & $1536,25 \mathrm{~b} \quad \mathrm{~A}$ \\
\hline Milheto-forrageiro & 1916,68 a $B$ & 3047,50 a $\mathrm{A}$ & 1784,05 a B & 2815,00 a $\mathrm{A}$ \\
\hline Capim-pé-de-galinha & 1860,00 a $\mathrm{A}$ & $2023,75 \mathrm{~b} \quad \mathrm{~A}$ & 992,00 a $\mathrm{A}$ & $1038,75 \mathrm{~b} A$ \\
\hline Capim-braquiária & 2851,25 a $\mathrm{A}$ & $2956,25 \mathrm{ab} \mathrm{A}$ & 1793,75 a $B$ & 3235,00 a $\mathrm{A}$ \\
\hline DMS (na linha) & \multicolumn{2}{|c|}{781,70} & \multicolumn{2}{|c|}{589,19} \\
\hline DMS (na coluna) & \multicolumn{2}{|c|}{1005,67} & \multicolumn{2}{|c|}{1097,10} \\
\hline Test. s/ palha trat. c/ herb. ${ }^{(1)}$ & \multicolumn{2}{|c|}{2973,75} & \multicolumn{2}{|c|}{1810,13} \\
\hline Test. s/ palha e capinada ${ }^{(2)}$ & \multicolumn{2}{|c|}{2837,50} & \multicolumn{2}{|c|}{2837,50} \\
\hline Test. s/ palha ${ }^{(3)}$ & \multicolumn{2}{|c|}{500,00} & \multicolumn{2}{|c|}{500,00} \\
\hline
\end{tabular}

Com base no teste de Tukey a 5\% de probabilidade, médias seguidas de letra minúscula, nas colunas, comparam tipos de cobertura dentro de cada nível de palha e, letras maiúsculas, nas linhas, comparam os dois níveis para cada cobertura. $\left({ }^{1}\right)$ Testemunha sem palha e tratada com os herbicidas. $\left({ }^{2}\right)$ Testemunha sem palha e capinada. $\left({ }^{3}\right)$ Testemunha sem palha e mantida infestada.

Para produtividade de grãos, no primeiro ano, não ocorreram diferenças significativas entre as coberturas nos seus menores níveis de palha. No maior nível de palha, quando aplicado diclosulam, houve menor produtividade sobre cobertura de capim pé-de-galinha e, para imazaquin, sobre sorgo e capim pé-de-galinha (Tabela 9).

Nas parcelas pulverizadas com diclosulam, constatou-se, por contrastes, nas plantas da testemunha mantida infestada, menor produtividade de grãos, diferindo dos demais tratamentos $\left(\mathrm{F}_{\mathrm{c}}=67,78^{* *}\right)$. A testemunha tratada com diclosulam não diferiu da testemunha capinada $\left(\mathrm{F}_{\mathrm{c}}=0,17\right)$, as quais não diferiram dos dois níveis de palha de capim braquiária $\left(\mathrm{F}_{\mathrm{c}}=0,00\right)$, do maior nível de milheto forrageiro $\left(F_{c}=0,25\right)$ e do menor de sorgo $\left(F_{c}=3,36\right)$. Quando aplicado o imazaquin, a testemunha mantida infestada não diferiu dos dois níveis de 
capim pé-de-galinha $\left(\mathrm{F}_{\mathrm{c}}=3,59\right)$. A testemunha tratada com imazaquin diferiu da capinada $\left(\mathrm{F}_{\mathrm{c}}=10,68^{* *}\right)$, que resultou em maior produtividade de grãos, não diferindo significativamente dos maiores níveis de palha de capim braquiária $\left(\mathrm{F}_{\mathrm{c}}=1,59\right)$ e milheto forrageiro $\left(F_{c}=0,00\right)$. As plantas da testemunha tratada com imazaquin tiveram produtividade similar à das plantas de soja dos dois níveis de cobertura de sorgo $\left(\mathrm{F}_{\mathrm{c}}=0,05\right)$ e às dos menores níveis de milheto forrageiro $\left(\mathrm{F}_{\mathrm{c}}=0,00\right)$ e capim braquiária $\left(\mathrm{F}_{\mathrm{c}}=0,00\right)$.
No ano seguinte, nos dois níveis, as plantas de soja crescidas sobre palha de sorgo tiveram menor produtividade de grãos, sendo no menor nível, a cobertura de milheto forrageiro não diferiu da de sorgo (Tabela 10). Os níveis de palha diferiram entre si apenas para sorgo, mostrando que a adição deste resíduo vegetal ao solo resultou em perdas de $26 \%$ e $30 \%$, respectivamente, comparado ao seu menor nível de palha e ao valor médio das testemunhas sem palha tratadas com os herbicidas.

Tabela 10. Produtividade de grãos de soja crescida sobre quatro tipos de cobertura e dois níveis de palha, tratada com os herbicidas diclosulam e imazaquin, aplicados em pré-emergência, além das testemunhas (sem palha). Uberlândia (MG), $2004 / 2005$

\begin{tabular}{|c|c|c|c|}
\hline \multirow{2}{*}{ Tipos de cobertura } & \multicolumn{3}{|c|}{ Níveis de palha $\left(\mathrm{t} \mathrm{ha}^{-1}\right)$} \\
\hline & 3,5 & & 5,8 \\
\hline & +2 & $-\mathrm{kg} \mathrm{ha}^{-1}$ & 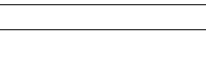 \\
\hline Sorgo & 2990,19 c A & & 2225,66 c B \\
\hline Milheto-forrageiro & 3330,99 bc A & & $3303,97 \mathrm{~b} \quad \mathrm{~A}$ \\
\hline Capim-pé-de-galinha & $3659,48 \mathrm{ab} A$ & & 3866,15 a $\mathrm{A}$ \\
\hline Capim-braquiária & 3976,14 a $A$ & & 3759,32 a $\mathrm{A}$ \\
\hline DMS (na linha) & & 266,66 & \\
\hline DMS (na coluna) & & 400,67 & \\
\hline Testemunha sem palha e tratada com diclosulam & & 3497,12 & \\
\hline Testemunha sem palha e tratada com imazaquin & & 2898,32 & \\
\hline Testemunha sem palha e capinada & & 3607,12 & \\
\hline Testemunha sem palha e mantida infestada & & 1528,23 & \\
\hline
\end{tabular}

Com base no teste de Tukey a 5\% de probabilidade, médias seguidas de letra minúscula, nas colunas, comparam tipos de cobertura dentro de cada nível de palha e, letras maiúsculas, nas linhas, comparam níveis para cada cobertura.

Pela comparação por contrastes, verificou-se que a testemunha mantida infestada propiciou menor produtividade de grãos, diferindo de todos os tratamentos $\left(F_{c}=240,63^{* *}\right)$. Não ocorreram diferenças significativas entre a testemunha capinada e a tratada com diclosulam $\left(\mathrm{F}_{\mathrm{c}}=0,47\right)$, assim como entre elas e os dois níveis de capim pé-de-galinha $\left(\mathrm{F}_{\mathrm{c}}=3,42\right)$ e capim braquiária $\left(\mathrm{F}_{\mathrm{c}}=7,68\right)$. A testemunha tratada com imazaquin diferiu do maior nível de palha de sorgo $\left(\mathrm{F}_{\mathrm{c}}=17,43^{* *}\right)$, com maior média, no entanto, não diferiu do seu menor nível $\left(\mathrm{F}_{\mathrm{c}}=0,32\right)$.

Pelos resultados, constatou-se que os herbicidas diclosulam e imazaquin não afetaram as plantas de soja. Em alguns casos, houve efeito negativo do imazaquin, decorrente, no entanto, do controle insatisfatório das plantas daninhas. Outros trabalhos de pesquisa também comprovaram a seletividade da soja a esses herbicidas. Leite et al. (2000), avaliando 12 cultivares de soja, relataram que os herbicidas diclosulam (35 $\mathrm{g} \mathrm{ha}^{-1}$ ) e imazaquin (150 $\left.\mathrm{g} \mathrm{ha}^{-1}\right)$, aplicados em condições de présemeadura com incorporação ao solo, não causaram prejuízos a nenhum dos genótipos estudados, em relação à testemunha capinada. BRIGHENTI et al. (2002), mencionaram que aos 17 dias após a aplicação de $140 \mathrm{~g}^{\mathrm{ha}^{-1}}$ de imazaquin, as percentagens de intoxicação das plantas de soja foram baixas, atingindo valor máximo de $5 \%$ para a cultivar Embrapa 58. Aos 45 dias, o maior valor obtido foi de $7,2 \%$ para a BRS 156 . Quanto à altura das plantas, apenas a cultivar BRS 156 foi sensível ao herbicida. Contudo, o imazaquin não afetou o estande da cultura e o produtividade de grãos de nenhum dos 17 genótipos de soja estudados. Em outro estudo, o herbicida diclosulam, aplicado em pré-semeadura com incorporação ao solo e em préemergência, na dose de $35 \mathrm{~g} \mathrm{ha}^{-1}$, não afetou a produtividade de grãos de soja (REDDY, 2000). 


\section{CONCLUSÕES}

1. No primeiro ano, plantas de Eleusine coracana tornaram-se infestantes na cultura da soja sobre cobertura de capim pé-de-galinha. Devido à ausência de controle dessa espécie pelos herbicidas diclosulam e imazaquin, a convivência entre elas e a cultura refletiu negativamente nas plantas de soja.

2. O herbicida imazaquin afetou, indiretamente, as plantas de soja, em virtude do controle insatisfatório das plantas daninhas.

3. Nas plantas de soja crescidas sobre cobertura de capim braquiária (nos dois anos do estudo) e de capim pé-de-galinha (no segundo ano) observaram-se maior produtividade de grãos, acúmulo de massa e altura de plantas. Os resíduos vegetais de sorgo influenciaram negativamente o desenvolvimento das plantas de soja, nos dois anos.

4. Quanto aos níveis de palha, houve diferença entre eles para milheto forrageiro (no primeiro ano) e sorgo (no segundo ano). O menor nível de milheto forrageiro e o maior de sorgo ocasionaram prejuízos às plantas de soja.

\section{REFERÊNCIAS}

BRIGHENTI, A.M.; ADEGAS, FS.; BORTOLUZI, E.S.; ALMEIDA, L.A.; VOLL, E. Tolerância de genótipos de soja aos herbicidas trifluralin e imazaquin. Planta Daninha, Viçosa, v. 20, n. 1, p. 63-69, 2002.

CARVALHO, M.A.C.; ATHAYDE, M.L.F.; SORATTO, R.P.; ALVES, M.C.; ARF, O. Soja em sucessão a adubos verdes nos sistema de plantio direto e convencional em solo de Cerrado. Pesquisa Agropecuária Brasileira, Brasília, v. 39, n. 11, p. 1141$1148,2004$.
CORREIA, N.M.; SOUZA, I.F.; KLINK, U.P. Palhadas de sorgo associadas ao herbicida imazamox no desenvolvimento da cultura da soja em sucessão. Revista Brasileira de Herbicidas, Brasília, v. 4, n. 2/3, p. 91-96, 2002.

FEDERAÇÃO BRASILEIRA DE PLANTIO DIRETO NA PALHA. 2005. Disponível em <http:/ / www.febrapdp.org.br> Acesso em: 12 de junho de 2005.

GEOCITIES. 2006. Disponível em <http:// www.br.geocities.com/agbcg/orelevoc.doc> Acesso em: 24 de abril de 2006.

INDERJIT; KEATING, K.I. Allelopathy: Principles, procedures, processes, and promises for biological control. Advances in Agronomy, San Diego, v. 67, p. 141-231, 1999.

LEITE, C.R. F.; ALMEIDA, J.C.V.; PRETE, C.E.C. Sensibilidades de cultivares de soja (Glycine max) aos herbicidas diclosulam e flumetsulam. Planta Daninha, Botucatu, v. 18, n. 1, p. 103-122, 2000.

PASQUALETTO, A. Sucessão de culturas como alternativa de produção em plantio direto no cerrado. 1999. 135f. Tese (Doutorado em Fitotecnia)- Universidade Federal de Viçosa, Viçosa.

PEIXOTO, M.F.; SOUZA, I.F. Efeitos de doses de imazamox e densidades de sorgo (Sorghum bicolor (L.) Moench) em soja (Gyicine Max (L.) Merril) sob plantio direto. Ciência e Agrotecnologia, Lavras, v. 26, n. 2, p. 252-258, 2002.

REDDY, K.N. Weed control in soybean (Glycine max) with cloransulam and diclosulam. Weed Technology, Champaign, v. 14, n. 2, p. $293-297,2000$.

RICE, E.L. Allelopathy. 2. ed. Orlando: Academic Press, 1984. 422p.

ROTH, C. M.; SHROYER, J. P.; PAULSEN, G. M. Allelopathy of sorghum on wheat under several tillage systems. Agronomy Journal, Madison, v. 92, n. 5, p. 855-860, 2000.

SANTOS, H.P.; WOBETTO, C.; PEREIRA, L.R. Rotação de culturas em Guarapuava. x. efeitos das culturas de inverno sobre características agronômicas da soja. Pesquisa Agropecuária Brasileira, Brasília, v. 26, n. 9, p. 1551-1561, 1991. 